\title{
Coping and Resilience: Two Peas in a Pod? A Mixed- methods Study on the Association Between Coping and Resilience among Caretakers of School-going Children with Disabilities in Uganda
}

\section{Mariam Namasaba}

The University of Tokyo

Neo Kazembe

The University of Tokyo

Georgina Seera

Kyoto University

Ali Ayub Baguwemu ( $\square$ alibaguwemu2020@gmail.com )

Kyambogo University

\section{Research Article}

Keywords: Children with disabilities, coping skills, social support

Posted Date: August 30th, 2021

DOl: https://doi.org/10.21203/rs.3.rs-794604/v1

License: (c) (i) This work is licensed under a Creative Commons Attribution 4.0 International License.

Read Full License 


\section{Abstract}

\section{Background}

In Africa, caretakers of children with disabilities face stigma and report feeling isolated. The caretakers may take their children to school in the hope of finding solace from grim societal norms. However, schools for children with disabilities are often too ill-equipped to support the children or their caretakers. No study has examined how structural settings (like the type of school) may frame the association between coping and resilience. Thus, this study examined the association between coping and resilience among caretakers of school-going children with disabilities in Uganda.

\section{Methods}

The study used mixed methods to survey 621 caretakers of children with disabilities in Kampala district, Uganda. Hierarchical cluster analysis followed by binary logistic regression was conducted to examine the association between school type and caretakers' coping patterns. Hierarchical linear regression was then employed to assess the association between coping and resilience with the type of school and other covariates. Qualitative data were analyzed through thematic analysis. Qualitative and quantitative results were triangulated with a convergent joint display.

\section{Results}

Caretakers of children in inclusive schools were more likely to use adaptive coping skills than caretakers of children in special needs schools (Adjusted Odds Ratio (AOR) $=1.5 ; p=0.04 ; 95 \% \mathrm{Cl}=1.02-2.30$ ). Caretakers of children in special needs schools had significantly higher resilience than caretakers of children in inclusive schools $\left(B=2.65 ; S E \_B=1.21 ; p=0.02 ; n=621\right)$. Caretakers who received social support from the school had significantly higher resilience than caretakers who received social support from informal sources $\left(B=2.33 ; E_{-} B=1.05 ; p=0.03 ; B=1.87\right)$

\section{Conclusion}

This study underscores the importance of structural factors, such as the school type, in framing caretakers' psychological outcomes. Schools that provide social support to caretakers play a crucial mediating role in how caretakers cope and influence their ability to adapt to the challenges they face. Therefore, schools for children with disabilities are an avenue that can be leveraged to support families and improve the psychological health outcomes of children and their caretakers.

\section{Background}

Children with disabilities are more reliant on their caretakers than those without disabilities [1, 2]. Caretakers of children with disabilities report feeling overwhelmed and having less time for themselves [3]. The caretakers are often segregated in their communities and sometimes experience anxiety about their children's future [4]. In addition, the caretakers experience loneliness due to abandonment from 
relatives [5]. In Africa, caretakers of children with disabilities are often despised and referred to as witches [6]. Similarly, their children are believed to be cursed and abodes for evil spirits. Hence the experience of children with disabilities in public settings is formidable $[1,7]$.

In Uganda, grim societal norms shape the experiences of children with disabilities and their caretakers [8, 9]. In inclusive schools, the children are mocked by their peers and sometimes receive impartial attention from school staff compared to their non-disabled peers [10]. Moreover, schools often shun children with disabilities even though they consider those with physical disabilities more acceptable $[11,12]$. Of the 2.5 million children with disabilities in Uganda, $6 \%$ are enrolled in primary schools, and $10 \%$ of those enrolled complete grade five [10,13]. A caretaker's coping skills of dealing with the array of challenges dictate their resilience level. Studies show that caretakers who receive social support tend to have high resilience [14-16]. It follows that schools with internal support systems for caretakers and children with disabilities may impact their mental health outcomes, such as the level of resilience $[17,18]$.

Resilience, the ability to thrive and overcome a challenging situation [19], has been linked to social support in previous studies. According to some studies, social support is one of the main protective factors for building individuals' resilience $[15,20,21]$. Caretakers who receive social support are more likely to use adaptive coping skills than those who do not receive any social support [22]. Moreover, schools offering social support to children with disabilities enable them to cope with the emotional distress of transitioning from primary to secondary school [23]. Therefore, caretakers whose children receive adequate care and support at school may have less anxiety about their children's well-being [22].

While previous studies reveal an interplay between social support, coping, and resilience, they do not provide insight on how schools may frame the coping skills and level of resilience among caretakers of children with disabilities. This study posits that schools can be the factor (pod) that frames caretakers' coping and resilience outcomes (two peas). Thus, this study examined the association between coping and resilience among caretakers of school-going children with disabilities in Uganda.

\section{Methods}

\subsection{Study design and site}

This mixed-methods study was conducted in inclusive and special needs schools in the Kampala Capital City Authority, Uganda. All schools for children with disabilities in Kampala were invited to participate. A setting was considered a school if it was registered with the Uganda National Examination Board to offer academic services and conduct national standardized exams. Out of the 15 eligible schools, eight schools were inclusive, and seven were special needs schools. The study collected data from caretakers of school-going children with disabilities between May and September 2018.

\subsection{Study participants, recruitment, and data collection}




\subsubsection{Quantitative phase}

The study targeted all caretakers of children with disabilities in the participating schools. A caretaker was the primary guardian of a child with disabilities, who had lived with them six months or more, and was at least 18 years of age [24]. The caretakers had to speak either English or Luganda (The most common local language used in Kampala). The researcher ( $\mathrm{MN}$ ) sent circulars to all eligible caretakers, inviting them to an information and data collection seminar. Caretakers who agreed to join the study were screened based on the eligibility criteria of age, language, role as a caretaker, and time spent caring for the child. After screening, two research assistants distributed questionnaires to participants, explained all questionnaire items and demonstrated how to fill in responses. Caretakers took 30-40 minutes to answer the questionnaire. Caretakers who could not read had the questions read aloud for them, and they selected responses themselves. The questionnaires were pre-tested to check their content validity and suitability for use in the Ugandan context.

\subsubsection{Qualitative phase}

Caretakers were purposively selected to reflect job position variation in school, gender, and relationship with the child. Two research assistants used semi-structured guides to conduct in-depth interviews in Luganda. The interview guides had open-ended questions spanning themes on caretakers' perceptions of coping and resilience. The data were transcribed verbatim and later translated into English for analysis.

\subsection{Questionnaires and measures}

All questionnaires were translated from English to Luganda by two language experts. Two other language experts translated back the questionnaire items for confirmation. In addition, cognitive interviews were done with three caretakers who were selected using simple random sampling.

\subsubsection{Assessment of coping}

The study used the Brief Cope questionnaire to assess coping skills [25]. Brief Cope is a self-administered questionnaire with 14 subscales and a total of 28 items. The subscales include self-distraction, active coping, denial, substance use, emotional support, instrumental support, behavioral disengagement, venting, positive reframing, planning, humor, acceptance, religion, and self-blame.

\subsubsection{Assessment of resilience}

The level of resilience was assessed using the Resilience Scale for Adults [26]. The Resilience scale for adults has 28 items that evaluate the level of resilience using a score. The highest score is 140 , while the 
least possible score is 28 . Respondents answered $1=$ not at all, $2=$ a little, $3=$ somewhat, $4=$ quite a bit, and $5=$ a lot.

\subsection{Measurement of covariates}

The study covariates were grouped into two categories. First were structural factors. These were: type of school and source of social support (schools, religious institutions, family, and friends). Second, sociodemographic variables. These were: caretaker characteristics (employment, age, marital status, level of education, and religious affiliation) and children's characteristics (age, sex type, and severity of disability).

\subsection{Data analysis}

\section{Quantitative analysis}

The profiles of the children were summarized by using descriptive statistics.

\section{Assessing coping patterns among caretakers}

Agglomerative hierarchical clustering was used to discern coping patterns and predict caretakers' likelihood of using them [27]. The between-groups method was used to link the 14 Brief Cope subscales based on an interval of Pearson's correlation. Afterward, binary logistic regression examined the link between school type and coping patterns among caretakers.

\section{Examining the association between coping and resilience among caretakers}

Independent sample t-tests and ANOVA were employed to test for statistical differences in the level of resilience among caretakers, based on the type of school. Five hierarchical linear regression models were used to assess the association between coping and resilience with structural factors.

The first model included coping patterns discerned through agglomerative hierarchical cluster analysis. The second model included the 14 subscales of coping. In the third model, structural factors were added. The fourth and fifth models considered socio-demographic characteristics of caretakers and children, respectively. Multi-collinearity and the dispersion of outliers were checked in situ. Statistical Package for Social Sciences 24th version (SPSS 24) was used for all analyses.

\section{Qualitative analysis}


Data from in-depth interviews were transcribed and translated into English. Three researchers went through the codes independently and reached a consensus on the themes. A joint display was used to integrate quantitative and qualitative data $[28,29]$.

\section{Ethical considerations}

Ethical approval was obtained by the Research Ethics Committee of The University of Tokyo (SN 11990), the Institutional Review Board of Makerere University (P 578), and the Uganda National Council of Science and Technology (SS 4656). Participation in the study was voluntary, and caretakers were free to skip uncomfortable questions or withdraw from the study at any time. No names were recorded on the questionnaires for confidentiality purposes.

\section{Results}

\subsection{Quantitative phase}

Fifteen schools with a potential population of 1000 caretakers accepted the invitation to participate in the study. Of these, eights were inclusive schools, and seven were special needs schools. A total of 670 caretakers $(67 \%)$ responded to the study invitation. One school (49 caretakers) dropped out of the study, citing administrative inconveniences. Thus, the final analysis included 621 caretakers from 14 schools.

\subsubsection{Socio-demographic characteristics of caretakers and children}

The socio-demographic characteristics of the caretakers and children are summarized in Table 1 . The mean age of caretakers was 35 years, and the majority were female caretakers (81.0\%). More than half $(56.8 \%)$ of the caretakers were employed, with about a quarter $(25.9 \%)$ having completed secondary school.

Table 1

Socio-demographic characteristics of caretakers and children, by type of school $(n=621)$ 
Variable Category Special needs school Inclusive schools [mean age; $\mathrm{SD}=35.0 ; \quad$ [mean age; $\mathrm{SD}=$ 10.5] $41.20 ; 10.0]$

Caretakers' characteristics

\begin{tabular}{|c|c|c|c|c|}
\hline \multirow[t]{2}{*}{ Age (yrs.) } & $18-25$ & 72 & 4 & 76 (12.2) \\
\hline & $26-35$ & 202 & 49 & $251(40.4)$ \\
\hline & $36-44$ & 111 & 63 & $174(28.0)$ \\
\hline & 45 and above & 68 & 52 & $120(19.3)$ \\
\hline & & 453 & 168 & 621 \\
\hline \multirow[t]{3}{*}{ Gender } & Male & 90 & 28 & 118 (19.0.) \\
\hline & Female & 363 & 140 & $503(81.0)$ \\
\hline & & 453 & 168 & 621 \\
\hline \multirow[t]{3}{*}{ Employment } & Yes & 235 & 118 & $353(56.8)$ \\
\hline & No & 218 & 50 & $268(43.2)$ \\
\hline & & 453 & 168 & 621 \\
\hline \multirow[t]{7}{*}{$\begin{array}{l}\text { Education } \\
\text { level }\end{array}$} & $\begin{array}{l}\text { Incomplete } \\
\text { primary }\end{array}$ & 75 & 62 & $137(22.1)$ \\
\hline & Complete primary & 56 & 20 & $76(12.2)$ \\
\hline & $\begin{array}{l}\text { Incomplete } \\
\text { secondary }\end{array}$ & 133 & 28 & $161(25.9)$ \\
\hline & $\begin{array}{l}\text { Complete } \\
\text { secondary }\end{array}$ & 50 & 16 & $66(10.6)$ \\
\hline & $\begin{array}{l}\text { Higher than } \\
\text { secondary }\end{array}$ & 25 & 9 & $34(5.5)$ \\
\hline & $\begin{array}{l}\text { Complete } \\
\text { university }\end{array}$ & 66 & 23 & $89(14.3)$ \\
\hline & $\begin{array}{l}\text { Vocational } \\
\text { school }\end{array}$ & 47 & 10 & $57(9.2)$ \\
\hline
\end{tabular}


Children's characteristics

\begin{tabular}{|c|c|c|c|c|}
\hline \multirow[t]{4}{*}{ Age (yrs.) } & & $\begin{array}{l}\text { [mean age; } S D=8.51 ; \\
4.60]\end{array}$ & $\begin{array}{l}{[\text { mean; SD = 11.15; }} \\
3.55]\end{array}$ & \\
\hline & $3-6$ & 158 & 7 & $175(28.2)$ \\
\hline & $7-13$ & 223 & 104 & $327(52.7)$ \\
\hline & $14-8$ & 72 & 47 & 119 (19.1) \\
\hline & & 453 & 168 & 621 \\
\hline \multicolumn{5}{|l|}{ Gender } \\
\hline & Female & 239 & 65 & 304 (40.9) \\
\hline & Male & 214 & 103 & $317(51.0)$ \\
\hline & & 453 & 168 & 621 \\
\hline \multicolumn{5}{|l|}{$\begin{array}{l}\text { Type of } \\
\text { disability }\end{array}$} \\
\hline & Physical & 254 & 88 & $342(55.1)$ \\
\hline & Intellectual & 129 & 60 & 189 (30.4) \\
\hline & Multiple & 70 & 20 & $90(14.5)$ \\
\hline & & 453 & 168 & 621 \\
\hline \multicolumn{5}{|l|}{ Severity } \\
\hline & Mild & 48 & 18 & 66 (10.6) \\
\hline & Moderate & 158 & 60 & 218 (35.1) \\
\hline & Severe & 144 & 57 & 201 (32.4) \\
\hline & Very severe & 103 & 33 & $136(21.9)$ \\
\hline
\end{tabular}

The children had a mean age of nine years. The majority (51\%) were female children, and over half (55\%) had physical disabilities. Of all, $45 \%$ were rated by their caretakers as having mild to moderate impairments.

\subsubsection{Coping patterns among caretakers of children with disabilities}

Two patterns of coping were identified: adaptive and maladaptive coping. The first cluster (38\%) was named adaptive coping. The cluster combined Brief cope subscales of emotional and instrumental 
support, active, planning, acceptance, religion, and positive reframing. Of the seven subscales, emotional and instrumental support had the strongest correlation $(r=0.5)$.

Figure 1 shows the coping patterns (adaptive and maladaptive coping) discerned through agglomerative hierarchical cluster analysis. The second cluster- $62 \%$ was named maladaptive coping. The cluster combined Brief cope subscales of self-distraction, venting, denial, self-blame, behavioral disengagement, humor, and substance. Self-distraction and venting had the strongest correlation among the seven subscales in the second cluster $(r=0.3)$.

\section{Factors associated with coping patterns among caretakers}

Table 2 shows the multivariate binary logistic regression of the association between school type and coping patterns $(P C A=68.4 \%)$. The adjusted odds ratio $(A O R)$ is reported. Caretakers of children in inclusive schools were more likely to use adaptive coping patterns than caretakers of children in special needs schools ( $A O R=1.5 ; p=0.04)$. Caretakers who received any form of social support (from schools and informal networks) were approximately twice as likely to use adaptive coping skills than caretakers who did not receive any social support (School social support: $A O R=1.53 ; p=0.01$; informal social support: $A O R=1.78 ; p=0.01)$. Caretakers of children aged between $3-6$ years were less likely to use adaptive coping patterns than caretakers of older children $(A O R=0.38, p=0.01)$.

Table 2

Binary logistic regression of the association between school type and coping patterns among caretakers $(n=621)$

\subsubsection{Associated between coping resilience among caretakers.}

Hierarchical multiple linear regression was conducted in five models to examine the association between coping and resilience among caretakers. The fifth model, shown in Table 3, had the most significant change in R-square (Model 5: R-square $=24.4 \% ; p<0.01$ ). Caretakers of children in special needs schools had higher resilience scores than caretakers of children in inclusive schools $\left(B=2.64 ; S_{-} B=5.01 ; p=\right.$ 0.03). Caretakers who used adaptive coping patterns (active coping, emotional support, instrumental support, active coping, and religion) tended to have significantly high resilience scores $\left(B=1.24 ; S E \_B=\right.$ $0.48 ; p=0.01, B=0.99 ; S E \_B=0.40 ; p=0.01, B=1.36 ; S E \_B=0.30 ; p<0.001, B=1.13 ; S E \_B=0.36 ; p<$ $0.001)$. In contrast, caretakers who used maladaptive coping patterns (behavioral disengagement and self-blame) had significantly low resilience scores $\left(B=-0.66\right.$; $S E \_B=0.30 ; p=0.02, B=-0.66$; $S E \_B=0.28$; $p=0.02)$. Caretakers who received social support from school and had older children also had high 


\begin{tabular}{|c|c|c|c|c|}
\hline \multirow[t]{8}{*}{ Child characteristics } & \multirow[t]{2}{*}{ Variable } & \multirow[t]{2}{*}{ AOR } & \multicolumn{2}{|c|}{$95 \% \mathrm{Cl}$} \\
\hline & & & Lower & Upper \\
\hline & Child's age group* & 0.38 & 0.21 & 0.66 \\
\hline & (3-6 years) & & & \\
\hline & (Ref: maladaptive coping skills) & & & \\
\hline & Child's sex & 0.91 & 0.63 & 1.31 \\
\hline & (Boy) & & & \\
\hline & Type of disability & 0.77 & 0.45 & 1.32 \\
\hline \multirow[t]{4}{*}{ School characteristics } & Type of school * & 1.53 & 1.02 & 2.30 \\
\hline & (Ref: inclusive schools) & & & \\
\hline & School social support* & 1.78 & 1.20 & 2.57 \\
\hline & Informal social support* & 2.02 & 1.15 & 3.54 \\
\hline \multirow[t]{7}{*}{ Caretaker characteristics } & Caretaker's education level & 1.05 & 1.00 & 1.14 \\
\hline & Employment status & 1.09 & 0.74 & 1.59 \\
\hline & (Unemployment) & & & \\
\hline & Caretaker's age & 1.28 & 0.63 & 2.58 \\
\hline & (Ref: 18-25yrs.) & & & \\
\hline & Child's age * & 0.38 & 0.21 & 0.67 \\
\hline & (Ref: 3-6 yrs.) & & & \\
\hline
\end{tabular}

*: p-value<0.05; **: p-value<0.001; Ref: reference group, AOR: Adjusted odds ratio, $\mathrm{Cl}=$ confidence interval.

resilience scores $\left(B=2.33 ; S E_{-} B=1.05 ; p=0.03, B=1.87 ; S E \_B=0.09 ; p=0.02\right)$. Caretakers who received social support from informal sources showed no significant variation in their resilience scores $(B=2.48$; $\left.S_{-} B=1.46 ; p=0.09\right)$.

\section{Table 3}

Model 5 of hierarchical linear regression of factors associated with the resilience score among caretakers $(n=621)$ 


\begin{tabular}{|c|c|c|c|c|c|}
\hline & & & Lower & Upper & \\
\hline & Coping cluster & 2.58 & -1.02 & 6.18 & 1.83 \\
\hline & $\begin{array}{l}\text { (Ref: maladaptive coping } \\
\text { skills) }\end{array}$ & & & & \\
\hline & Self-distraction & -0.49 & -1.04 & 0.06 & 0.28 \\
\hline & Active coping * & 1.24 & 0.30 & 2.17 & 0.48 \\
\hline & Denial & 0.15 & -0.37 & 0.67 & 0.27 \\
\hline & Substance use & 0.66 & -0.55 & 1.88 & 0.62 \\
\hline & Emotional support * & 0.99 & 0.21 & 1.78 & 0.40 \\
\hline & Instrumental support ** & 1.36 & 0.66 & 2.06 & 0.36 \\
\hline & Behavioral disengagement* & -0.70 & -1.28 & -0.12 & 0.30 \\
\hline & Venting & 0.66 & 0.01 & 1.30 & 0.33 \\
\hline & Positive reframing & 0.40 & -0.26 & 1.05 & 0.33 \\
\hline & Planning & 0.64 & -0.17 & 1.45 & 0.41 \\
\hline & Humor & -0.15 & -0.85 & 0.56 & 0.36 \\
\hline & Acceptance & 0.67 & -0.08 & 1.43 & 0.38 \\
\hline & Religion ** & 1.13 & -0.43 & 1.84 & 0.36 \\
\hline & Self-blame * & -0.66 & -1.21 & -0.11 & 0.28 \\
\hline Structural factors & Type of school * & -2.64 & -5.01 & -0.27 & 1.21 \\
\hline & (Ref: special needs schools) & & & & \\
\hline & School social support* & 2.33 & 0.27 & 4.40 & 1.05 \\
\hline & Informal social support & 2.49 & 1.46 & -0.38 & 5.34 \\
\hline $\begin{array}{l}\text { Socio-demographic } \\
\text { factors }\end{array}$ & Caretaker's education level * & 0.62 & 0.08 & 1.15 & 0.27 \\
\hline & Employment status & 3.53 & 5.57 & 1.48 & 1.04 \\
\hline & (Ref: no employment) ** & & & & \\
\hline & Caretaker's age & 0.20 & -0.93 & 1.33 & 0.57 \\
\hline & (Ref: 18-25yrs.) & & & & \\
\hline
\end{tabular}


(Ref: 3-6 yrs.)

*: p-value<0.05; **: p-value<0.001; Ref: reference group, B: unstandardized co-efficient, $\mathrm{Cl}=$ confidence interval, SE_B = standard error for unstandardized co-efficient.

\subsection{Qualitative Results}

The qualitative study examined caretakers' perceptions of coping and resilience. Table 4 shows the characteristics of participants in the qualitative study.

Table 4

Age and gender profiles of participants in the in-depth interviews $(n=43)$

\begin{tabular}{|llll|}
\hline Participant's job position & $\begin{array}{l}\text { Mean age } \\
\text { [range] }\end{array}$ & $\begin{array}{l}\text { Average years of experience } \\
\text { (range) }\end{array}$ & Gender (\%) \\
\hline School principal $(n=10)$ & $49[36-55]$ & 9 & Male (100) \\
\hline Class teacher $(n=5)$ & $36(19-50)$ & 10 & Male (63) \\
$\begin{array}{l}\text { Occupational therapist } \\
(n=2)\end{array}$ & $33(27-40)$ & 9.5 & Male (100) \\
\hline $\begin{array}{l}\text { Dormitory staff } \\
(n=6)\end{array}$ & $35(22-48)$ & 11 & $\begin{array}{l}\text { Female } \\
(90)\end{array}$ \\
Home caretakers $(n=20)$ & $34(18-55)$ & NA & Female \\
\hline
\end{tabular}

A total of 43 respondents were selected. Of all 25 caretakers were from inclusive schools, and 18 were from special needs schools. Among the key respondents, 10 were school principals, 5 were class teachers, 2 were occupational therapists, and 6 were dormitory staff. Among home caretakers, 20 interviews were conducted. Of all, 10 were parents of the children ( 5 fathers and five mothers), and 10 were other relatives (grandmothers and close relatives) primarily responsible for the child.

The qualitative methods and reporting of results followed the Consolidated Criteria for Reporting Qualitative Studies (COREQ) guidelines [30] and standard for reporting Qualitative Research (SRQR) [31]. A complete COREQ checklist is included as Supplementary Table 1. A STROBE statement is also provided as supplementary Table 2.

\subsubsection{Caretakers' perception of coping}


Two themes on coping were identified from the in-depth interviews with key respondents: disengaged and engaged coping. Quotes from respondents are cited to illustrate the thematic results. Pseudonyms were used instead of respondents' real names.

\section{Disengaged coping}

Caretakers who used disengaged coping had difficulty relating to their children. Key respondents explained that caretakers who were disengaged commonly denied and abandoned their children. A dormitory caretaker elucidated by saying:

"Some parents deny their children and say this child is not mine, they are adopted, yet you can see the resemblance; they consider these children as unimportant; these children always come last compared to others." (Dormitory staff: female, 48)

A school principal also echoed this theme:

"Male caretakers, especially fathers, deny their children saying in my lineage there are no deaf children; They do not even look at the children with love. For deaf children, facial expressions are important because that is how they judge emotions." (School principal: male, 52)

Another school principal also added to this voice and said:

"Some abandon their children here for years; they even deny the children saying they are adopted, yet one can see a striking resemblance." (School principal: male, 48)

In addition, disengaged caretakers were seen to be apathetic. Key respondents explained that apathetic caretakers rarely visited schools or sought support from them. The caretakers commonly had children dropping out of school.

"Some caretakers are unmotivated and want everything done for them; they want things on a silver platter; Even when I tell them to do something, they are not co-operative; they want me to do everything and expect miracles at the end of the school term."(Occupational therapist: male, 27)

"Some caretakers only do the bare minimum for these children." For example, Nammuddu's grandmother brings her back to school with USD 0.1 to use for the whole term. She says that is all she can afford, but I know it is not true; there are times Nammuddu stays at school for months after the school term ends; the grandmother says she cannot afford to pick her up (Dormitory staff: female, 48)

\section{Engaged coping.}

Caretakers who were oriented toward engaged coping were identified through their connection to their children. The caretakers tended to be proactive and had accepted their children's disabilities. In addition, 
such caretakers often sought support from school staff and health practitioners. Key respondents spotlighted this theme by saying:

"Some caretakers accept and learn to accommodate their children; they even learn to love them; We see them during school activities." (Class teacher: male, 40)

"There are those who seek more knowledge and skills to take care of their children. They partner with other people concerned with children with disabilities." (School principal: male, 55).

\subsubsection{Perception of resilience among caretakers}

Three themes on the perception of resilience were discerned from the interviews with caretakers. The themes identified were social support, socio-economic status, and spirituality.

\section{Social support}

Caretakers who received support from the school or their social networks felt hopeful and encouraged to take care of their children. One mother expressed gratitude for the empathy that she received from friends and other caretakers of children with disabilities.

"Support from friends makes me strong; I used to go to a private hospital and was alone, but when I started bringing the child to school, I saw others with children like mine and was welcomed by other caretakers; I got strength knowing I am not alone; I used to struggle in the beginning, but now I am okay." (Mother, 27)

Another mother explained that receiving support from professional health practitioners in school is vital for her child's well-being.

"I often bring Martina (not real name) here to see a physical therapist. That has been very helpful, and it refreshes my commitment to take care of her."(Mother, 32).

Another mother mentioned that the school's sign language classes had equipped her to communicate with and understand her child.

"When I come here (school) for sign language classes, I learn how to communicate with my child, and it motivates me; the school staff also give me advice, and it consoles me." (Mother,45)

\section{Socio-economic status}

Caretakers who had good socio-economic status (financial stability or high education level) were better able to deal with challenges and bounce back from challenging situations. Caretakers elucidated the 
themes through lamentations on their financial constraints.

"Sometimes, I do not make any money, so I cannot bring her to school or buy enough food for the family." (Grandmother, 60).

A key respondent re-enforced the theme by saying:

"Caretakers from well-off families are doing well. They can even hire private therapists and buy expensive medicines that others cannot afford; Financial stability enables them to seek healthcare services and buy assistive devices for their children." (Dormitory staff: 40)

Respondents affirmed the relevance of caretakers' education level:

"Highly educated caretakers can appreciate the value of bringing a child to school, so they always return their children and do everything they can to support them; less educated caretakers tend to have absent children or take them out of school altogether." (Class teacher: male, 49)

"Educated caretakers are concerned about their children; they are financially stable and have a positive attitude towards them." (Occupational therapist: male, 40)

\section{Spirituality}

Caretakers who believed in a higher power reported that they had peace and had learned to love and accept their children. The caretakers could reframe the disability in a positive light and therefore gain psychological tranquility.

"I pray a lot, so I know we will be okay; it gives me peace with the way my child is. God gave them to me that way-He alone knows why." (Mother, 35)

"Many people have favored me because of this child. He has been a blessing to us." (Mother, 25)

\subsection{Integration of results}

The quantitative and qualitative results were merged in a convergent joint display, as shown in Table 5 .

Table 5

A convergent joint display of quantitative and qualitative results 


\begin{tabular}{|c|c|c|c|}
\hline Quantitative r & sults & Qualitative results & Inference \\
\hline Variable & B & Quote & \\
\hline Social suppo & & & \\
\hline $\begin{array}{l}1 . \\
\text { Instrumental }\end{array}$ & $\underset{* \star}{1.36}$ & $\begin{array}{l}\text { "Caretakers who get support from institutions } \\
\text { fare better "(Class teacher, female, } 37 \text { ) }\end{array}$ & $\begin{array}{l}\text { Social support is impactful } \\
\text { for coping and building }\end{array}$ \\
\hline support & & $\begin{array}{l}\text { "I often take Martina to see a therapist. That } \\
\text { has been very helpful." (Mother, } 32 \text { ) }\end{array}$ & \\
\hline $\begin{array}{l}\text { Emotional } \\
\text { support }\end{array}$ & $\begin{array}{l}0.99 \\
\star\end{array}$ & $\begin{array}{l}\text { "Support from friends makes me strong." } \\
\text { (Mother, 27) }\end{array}$ & $\begin{array}{l}\text { Emotional support is } \\
\text { relevant for relieving } \\
\text { psychological distress }\end{array}$ \\
\hline $\begin{array}{l}\text { Socio-demog } \\
\text { Factors }\end{array}$ & phic & & \\
\hline $\begin{array}{l}\text { Education } \\
\text { level }\end{array}$ & ${ }_{*}^{0.62}$ & $\begin{array}{l}\text { "Educated caretakers appreciate services like } \\
\text { education or physiotherapy." } \\
\text { (Occupational therapist, } 27 \text { ) }\end{array}$ & $\begin{array}{l}\text { Education influences the } \\
\text { utilization of professional } \\
\text { services }\end{array}$ \\
\hline Employment & $\begin{array}{l}3.53 \\
\star \star\end{array}$ & $\begin{array}{l}\text { "Caretakers from well-off families are doing } \\
\text { well. They can even hire private therapists." } \\
\text { (Dormitory caretaker, 40) }\end{array}$ & $\begin{array}{l}\text { Good financial status is a } \\
\text { robust determinant of } \\
\text { resilience }\end{array}$ \\
\hline Coping skills & & & \\
\hline Religion & $\begin{array}{l}1.13 \\
\star \star\end{array}$ & $\begin{array}{l}\text { "I pray a lot, so I know we will be okay." } \\
\text { (Mother, 35) }\end{array}$ & $\begin{array}{l}\text { Believing in a higher power } \\
\text { gives caretakers hope for a } \\
\text { promising future. }\end{array}$ \\
\hline B: unstandarc & ed co- & fficient, $*$ : p-value $<0.05 ; * *$ : p-value $<0.01$ & \\
\hline
\end{tabular}

\section{Discussion}

This study had two main findings. First, the type of school was a significant predictor of coping and resilience among caretakers of school-going children with disabilities. Second, social support from schools was significantly associated with caretakers' level of resilience, while social support from informal sources had no significant association with the level of resilience among caretakers but was significantly associated with their coping patterns.

First, the present study revealed that the type of school was significantly associated with caretakers' coping patterns and level of resilience. Caretakers of children in special needs schools were more likely to have maladaptive coping patterns than caretakers of children in inclusive schools. Caretakers' maladaptive coping patterns may be linked to the age of their children. Previous studies show that caretakers of young children with disabilities are likely to have maladaptive coping patterns [32, 33]. In 
this study, the majority (80\%) of children below 13 years were in special needs, which may explain their caretakers' predisposition to using maladaptive coping patterns. The caretakers face bouts of anxiety and stress and are learning to care for their children [34]. However, as the children grow, the caretakers may accrue knowledge from lived experience and learn to adapt to the challenges of caring for their children.

Despite being more likely to use maladaptive coping skills, caretakers of children in special needs schools had significantly higher levels of resilience than caretakers of children in inclusive schools. The high level of resilience among caretakers may be attributed to resources available in special needs schools. Previous studies report that special needs schools hire staff skilled in special needs education, while inclusive schools often have mainstream staff lacking special needs education skills $[35,36]$. The trained staff in special needs schools support the caretakers, enabling them to bounce back despite having a precarious coping position. Caretakers in special needs schools are also encouraged by an environment that has children like their own. Study respondents highlighted this relative comparison in the quotes below:

"I get strengthened seeing that my child is faring better than some other children in this school." (Mother, 18).

"I used to go to a private hospital and was alone, but when I started bringing the child to school, I saw others with children like mine, and I got strength knowing I am not alone; in the beginning, it was difficult, but now I am okay." (Mother, 27)

On the contrary, inclusive schools, which are often government-aided in Uganda, face constraints of materials and staffing to the detriment of children and their caretakers [33]. Caretakers of children in inclusive schools bear the brunt of overcoming their challenges on their own. In addition, caretakers of children with disabilities in inclusive schools tend to compare them to children without disabilities. The caretakers then face heightened feelings of anxiety and disillusionment and, in turn, report a lower level of resilience [37].

Second, the study showed that school social support was associated with adaptive coping patterns and increased resilience among caretakers. In contrast, social support from friends, relatives, and spiritual leaders was significantly associated with coping patterns but not caretakers' level of resilience. Schools' social support is the impetus that launches caretakers toward adaptive coping and builds their resilience. Caretakers who receive support from professionals hired by schools (occupational therapists, sign language teachers, and counselors) can actively engage with their children's lives and gain a sense of being in control [38-40]. Moreover, in a school setting, caretakers feel secure to express their struggles without fear of criticism. One mother explained that her family and friends criticize her for talking about her struggles, but the school staff invites her to express them. The mother lamented that:

"I once told my sister that I felt exhausted due to the constant dependence of my child; she told me never to mention such things again because it is inhumane."(Mother, 32). 
Furthermore, schools sometimes provide financial aid to families, enabling caretakers to save on expenses such as school fees. The caretakers can then channel the savings to assistive devices or basic living necessities [4]. Nevertheless, caretakers greatly appreciated empathy from spiritual leaders and friends, acknowledging that it gave them the wherewithal to cope and adopt a positive outlook on life [40].

The current study used mixed methods to assess the association between coping and resilience among caretakers of school-going children with disabilities in Uganda. The study gives a comprehensive understanding of the interplay between schools, coping, and resilience. However, several potential methodological limitations could have influenced the results. First, the study used self-reported scales. Caretakers may have given biased responses due to misunderstanding or desire to be socially acceptable [41]. Second, the study used scales that had not yet been validated in Uganda. Thus, the study performed inductive validation and reliability analyses to confirm the construct validity and reliability scales. Third, the study used non-probabilistic sampling, which may have introduced a selection bias; hence the results of the study may not be extrapolated to either all caretakers of school-going children with disabilities or those whose children do not attend school. Lastly, the study's cross-sectional nature does not allow for conclusions on the direction of the relationships between school type, coping, and resilience.

\section{Conclusion}

The study indicates that although caretakers of children with disabilities in special needs schools are highly likely to use maladaptive coping skills, they receive social support from schools, enabling them to bounce back and attain significantly higher levels of resilience than caretakers of children in inclusive schools. These findings show that schools (both inclusive and special needs) are uniquely positioned to be a conduit for improving caretakers' mental health outcomes. Therefore, policymakers, researchers, and stakeholders should leverage the influence of schools for children with disabilities by equipping them with well-trained staff and materials to facilitate integrating children and their families into society.

\section{Abbreviations}

AOR: Adjusted odds ratio

COREQ: Consolidated Criteria for Reporting Qualitative Studies

Cl: Confidence Interval

SE_B: Standard Error for Unstandardized Co-efficient

SD: Standard Deviation

PCA: Principal Component Analysis 


\section{Declarations}

\section{Ethics approval and consent to participate}

All methods were carried out following the relevant guidelines and regulations. Ethical approval was obtained from the Graduate School of Medicine's Research Ethics Committee at The University of Tokyo. In Uganda, ethical approval was obtained through the Institutional Review Board of Makerere University School of Health Science (2020-29) and the Uganda National Council of Science and Technology (HS1027ES). The trial was registered on the University Hospital Medical Information Network Clinical Trials Registry (UMIN R000046712).

Participation in this study will be voluntary. Caretakers who agreed to participate provided written informed consent. Trained research assistants conducted interviews in secure and private places. The research assistants received a two-day training on data collection and ethical considerations before the data collection.

\section{Consent for publication}

Not applicable.

\section{Availability of data and materials}

The dataset and materials generated during the study are available on Open Science Framework [https://osf.io/3yrcn/?view_only=fbf8181dc5c444b08d08de539172c60b].

\section{Competing interests}

The authors declare that they have no competing interests.

\section{Funding}

No funding was obtained for the study.

\section{Authors' contributions}

$M N$ is the principal investigator of the study and wrote the initial draft of the manuscript. NK and $A A B$ provided overall guidance to design the study protocol. SG and NK provided a critical review of research methods, including sampling, data collection, and analysis. AAB is the principal investigator's primary 
supervisor and provided overall guidance to develop the study protocol and write it. All the authors have read and affirmed the final manuscript.

\section{Acknowledgments}

Masamine Jimba, Ken Ing Ong Cherng, Junko Kiriya, and Akira Shibanuma provided overall guidance on study design and manuscript preparation.

\section{References}

1. Heiman T. Parents of Children with Congenital Abnormalities: Resilience Coping and Future Expectations. J Dev Phys Disabil. 2009;14(2). https://doi.org//1015219514621.

2. Cadman D, Rosenbaum P, Boyle M, Offord DR. Children with chronic illness: family and parent demographic characteristics and psychosocial adjustment. Pediatrics. 1991;87(6):884-9.

3. Corrigan P, Markowitz FE, Watson A, Rowan D, Kubiak MA. An attribution model of public discrimination towards persons with mental illness. J Health Soc Behav. 2003:162-79.

4. Hastings RP, Kovshoff $\mathrm{H}$, Brown T, Ward NJ, Espinosa FD, Remington B. Coping strategies in mothers and fathers of preschool and school-age children with autism. Autism. 2005;9(4):377-91. https://doi.org/10.1177/1362361305056078.

5. Gona JK, Mung'ala-Odera V, Newton CR, Hartley S. Caring for children with disabilities in Kilifi, Kenya: what is the carer's experience? Child Care Health Dev. 2011;37(2):175-83. https://doi.org/10.1111/j.1365-2214.2010.01124.

6. Booyens M, Van Pletzen E, Lorenzo T. The complexity of rural contexts experienced by community disability workers in three southern African countries. Afri J Disabil. 2015;4(1):1-9. https://doi.org/10.4102/ajod.v4i1.167

7. Patterson JM. Integrating family resilience and family stress theory. J Marriage Fam. 2002;64(2):349 - 60. https://doi.org/10.1111/j.1741-3737.2002.00349.x

8. Shah A, Wheeler L, Sessions K, Kuule Y, Agaba E, Merry SP. Community perceptions of mental illness in rural Uganda: An analysis of existing challenges facing the Bwindi Mental Health Programme. Afr J Prim Health Care Fam Med. 2017;9(1):1-9. https://dx.doi.org/10.4102\%2Fphcfm.v9i1.1404.

9. Namazzi G, Hanson C, Nalwadda C, Tetui M, Nampijja M, Waiswa P, et al. Caring for children with neurodevelopmental disability: Experiences from caretakers and health workers in rural eastern Uganda. Plos One. 2020;15(7):e0236488. https://dx.doi.org/10.1371\%2Fjournal.pone.0236488

10. Okech JB, Yuwono I, Abdu WJ. Implementation of Inclusive Education Practices for Children with Disabilities and Other Special Needs in Uganda. AJEEL. 2021;8(1):97-102. https://doi.org/10.20448/journal.509.2021.81.97.102

11. Berjot S, Gillet N. Stress and coping with discrimination and stigmatization. Front Psychol. 2011;2:33. https://doi.org/10.3389/fpsyg.2011.00033. 
12. Kristensen K, Omagor-Loican M, Onen N, Okot D. Opportunities for inclusion? The education of learners with special educational needs and disabilities in special schools in Uganda. BJSE. 2006;33(3):139-47. https://doi.org/10.1111/j.1467-8578.2006.00429.

13. UBOS. Uganda National Household Survey 2016/2017. Kampala Uganda: Uganda Bureau of Statistics (UBOS) 2018. p. 300. https://www.ubos.org/wpcontent/uploads/publications/03_20182016_UNHS_FINAL_REPORT.pdf. Accessed on August 8, 2021.

14. Bonanno GA, Galea S, Bucciarelli A, Vlahov D. What predicts psychological resilience after disaster? The role of demographics, resources, and life stress. J Consul Clin Psychol. 2007;75(5):671. https://doi.org/10.1037/0022-006x.75.5.671.

15. Bhana A, Bachoo S. The determinants of family resilience among families in low-and middle-income contexts: a systematic literature review. S Afr J Psychol. 2011;41(2):131-9. http://dx.doi.org/10.1177/008124631104100202.

16. Opsomer S, De Lepeleire J, Lauwerier E, Pype P. Resilience in family caregivers of patients diagnosed with advanced cancer-unraveling the process of bouncing back from difficult experiences, a hermeneutic review. Eur J Gen Pract. 2020;26(1):79-85. https://dx.doi.org/10.1080\%2F13814788.2020.1784876.

17. Hussain A, Juyal I. Stress appraisal and coping strategies among parents of physically challenged children. J Indian Acad Appl Psychol. 2007;33(2):179-82.

18. Shin JY, Choi SW. Interventions to promote caregiver resilience. Curr Opin Support Palliat Care. 2020;14(1):60. https://dx.doi.org/10.1097\%2FSPC.0000000000000481.

19. Black K, Lobo M. A conceptual review of family resilience factors. J Fam Nurs. 2008;14(1):33-55. https://doi.org/10.1177/1074840707312237.

20. Vanderbilt-Adriance E, Shaw DS. Protective factors and the development of resilience in the context of neighborhood disadvantage. J Abnorm Child Psychol. 2008;36(6):887-901. https://doi.org/10.1007/s10802-008-9220-1.

21. Werner EE. Protective factors and individual resilience. In J. P. Shonkoff \& S. J. Meisels (Eds.), Handbook of early childhood intervention. 2000;2:115 - 32. Cambridge: Cambridge University. Presshttps://psycnet.apa.org/doi/10.1017/CB09780511529320.008.

22. Estes A, Munson J, Dawson G, Koehler E, Zhou X-H, Abbott R. Parenting stress and psychological functioning among mothers of preschool children with autism and developmental delay. Autism. 2009;13(4):375-87. https://doi.org/10.1177/1362361309105658.

23. Hughes LA, Banks P, Terras MM. Secondary school transition for children with special educational needs: a literature review. SFL. 2013;28(1):24-34. https://doi.org/10.1111/1467-9604.12012.

24. Okeke C, Mazibuko G. The experiences of parents of school children with special education needs: An empirical study. Mediterr J Soc Sci. 2014;5(15):227-. http://dx.doi.org/10.5901/mjss.2014.v5n15p227. 
25. Carver CS. You want to measure coping, but your protocol is too long: Consider the Brief Cope. Int $J$ Behav Med. 1997;4(1):92-100. https://doi.org/10.1207/s15327558ijbm0401_6.

26. Hjemdal O, Friborg O, Braun S, Kempenaers C, Linkowski P, Fossion P. The Resilience Scale for Adults: Construct validity and measurement in a Belgian sample. Int J Test. 2011;11(1):53-70. http://dx.doi.org/10.1080/15305058.2010.508570.

27. Sasirekha K, Baby P. Agglomerative hierarchical clustering algorithm-a. International Journal of Scientific and Research Publications. 2013;83:83.

28. Younas $A$, Pedersen $M$, Durante $A$. Characteristics of joint displays illustrating data integration in mixed-methods nursing studies. JAN. 2020;76(2):676-86. https://doi.org/10.1111/jan.14264.

29. Guetterman TC, Fetters MD, Creswell JW. Integrating quantitative and qualitative results in health science mixed methods research through joint displays. Ann Fam Med. 2015;13(6):554-61. https://doi.org/10.1370/afm.1865.

30. Tong A, Sainsbury P, Craig J. Consolidated criteria for reporting qualitative research (COREQ): a 32item checklist for interviews and focus groups.Int J Qual Health Care. 2007;19(6):349-57. https://doi.org/10.1093/intqhc/mzm042.

31. O'Brien BC, Harris IB, Beckman TJ, Reed DA, Cook DA. Standards for reporting qualitative research: a synthesis of recommendations. Acad Med. 2014;89(9):1245-51. https://doi.org/10.1097/acm.0000000000000388.

32. Mutepfa MM, Mpofu E, Chataika T. Inclusive education in Zimbabwe: Policy, curriculum, practice, family, and teacher education issues. Child Educ. 2007;83(6):342-6. https://doi.org/10.1080/00094056.2007.10522947.

33. Miles S, Singal N. The Education for All and inclusive education debate: conflict, contradiction or opportunity? Int J Incl Educ. 2010;14(1):1-15. https://doi.org/10.1080/13603110802265125.

34. Dabrowska A, Pisula E. Parenting stress and coping styles in mothers and fathers of pre-school children with autism and Down syndrome. J Intellec Disabil Res. 2010;54(3):266-80. https://doi.org/10.1111/j.1365-2788.2010.01258.

35. Furuta H, Alwis K. Teaching Students with Special Educational Needs in an Inclusive Educational Setting in Sri Lanka: Regular Class Teacher'View. J Int Coop Educat. 2017;19(2):1-18. https://doi.org/10.15027/44840.

36. Lwanga-Ntale C. Chronic poverty and disability in Uganda. 2003.Cornell: Cornell University ILR School.

37. Marquis SM, McGrail K, Hayes M. Mental health of parents of children with a developmental disability in British Columbia, Canada. J Epidemiol Community Health. 2020;74(2):173-8. https://dx.doi.org/10.1136\%2Fjech-2018-211698.

38. Tseng M-H, Chen K-L, Shieh J-Y, Lu L, Huang C-Y, Simeonsson RJ. Child characteristics, caregiver characteristics, and environmental factors affecting the quality of life of caregivers of children with cerebral palsy. Disabil Rehabil. 2016;38(24):2374-82. https://doi.org/10.3109/09638288.2015.1129451. 
39. Paster A, Brandwein D, Walsh J. A comparison of coping strategies used by parents of children with disabilities and parents of children without disabilities. Res Dev Disabil. 2009;30(6):1337-42. https://doi.org/10.1016/j.ridd.2009.05.010.

40. Hartley S, Ojwang P, Baguwemu A, Ddamulira M, Chavuta A. How do carers of disabled children cope? The Ugandan perspective. Child Care Health Dev. 2005;31(2):167-80. https://doi.org/10.1111/j.1365-2214.2004.00464.

41. Thibaut JW, Strickland LH. Psychological set and social conformity. J Pers. 1956. https://doi.org/10.1111/j.1467-6494.1956.tb01292.

42. World Health Organisation WB. World Report on Disability 2011. Report. Geneva, Switzerland: The World Health Organization, World Bank. Geneva: Switzerland, 2011. https://www.who.int/disabilities/world_report/2011/report.pdf. Accessed on August 9, 2021.

\section{Figures}




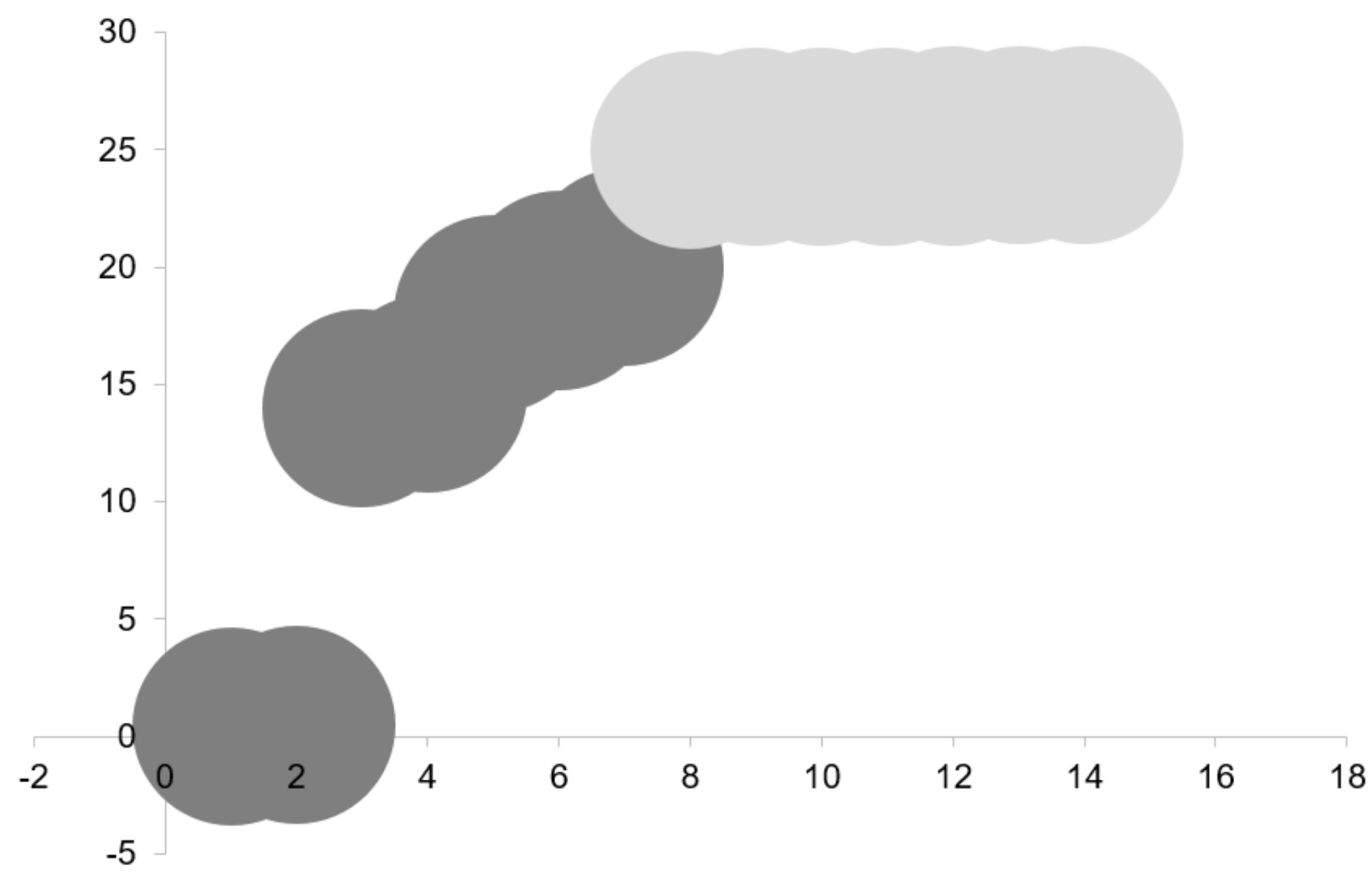

$\begin{array}{lll}\text { - Emotional support } & \text { - Instrumental support } & \bullet \text { Active coping } \\ - \text { Planning } & \text { - Acceptance } & \bullet \text { Religious coping } \\ \text { - Positive reframing } & \text { Self-distraction } & \text { Venting } \\ \text { - Denial } & \text { Self-blame } & \text { Behavioural-disengagement } \\ \text { Humor } & \text { Subtance use } & \end{array}$

Adaptive coping

Maladaptive coping

Figure 1

Linkage of Brief Cope subscales based on agglomerative hierarchical cluster analysis $(n=621)$

\section{Supplementary Files}

This is a list of supplementary files associated with this preprint. Click to download. 
- SupplementaryTable1COREQ.docx

- SupplementaryTable2STROBE.doc

Page 25/25 